\section{Ambient particulate matter and COPD in China: a challenge for respiratory health research}

\author{
Anke Hüls, Tamara Schikowski
}

Worldwide, COPD is an important cause of morbidity and mortality. The condition is increasing in prevalence, it is a major public health problem and it will remain a challenge for clinicians within the 21st century. ${ }^{1}$ COPD has become the third leading cause of death, ${ }^{2}$ resulting in 2.9 million deaths globally in 2013. ${ }^{3}$ The Global Burden of Diseases Study estimated that around 1.2 million premature deaths and 25 million disability-adjusted life-years annually in China alone could be attributed to air pollution. ${ }^{3}$ In recent years, evidence is growing that the exposure to ambient air pollution may contribute to the growing global burden of COPD. ${ }^{4}$ In many Western countries, levels of ambient air pollution have been improved with the setting of upper limits and better urban planning. However, air pollution in low/middle-income countries with rapid industrialisation, such as China, has become a major global problem. ${ }^{5}$ Severe air pollution events, with levels of fine particulate matter (PM) exceeding $690 \mu \mathrm{g} / \mathrm{m}^{3},{ }^{6}$ result in a health burden that has increased annually since 1990. ${ }^{7}$

The air pollution levels in cities in China are the biggest environmental challenge to public health. However, until now, there are only a limited number of publications on the adverse effects of air pollution on chronic respiratory diseases in China. ${ }^{7}$

There have been a large number of studies addressing the question of whether air pollution causes COPD leading to a number of meta-analyses, systematic and other reviews. ${ }^{8-11}$ However, the association has remained uncertain due to the variability in the studies and the limitation that the majority of studies were undertaken in areas with much lower pollution

Leibniz-Institut fur umweltmedizinische Forschung an der Heinrich-Heine-Universitat Dusseldorf gGmbH, Dusseldorf, Nordrhein-Westfalen, Germany

Correspondence to Dr Tamara Schikowski, Leibniz-Institut fur umweltmedizinische Forschung an der Heinrich-Heine-Universitat Dusseldorf gGmbH, Dusseldorf 40225, Germany; Tamara.Schikowski@ IUF-Duesseldorf.de levels than are currently seen in low/ middle-income countries. ${ }^{5}$ Liu et $a l^{12}$ provide an important contribution to the growing body of evidence that particulate matter increases the prevalence of COPD in a Chinese population with relatively high levels of ambient particulate matter in southern China. They conducted a cross-sectional study in Southern China in which they randomly selected seven clusters from four cities across Guangdong province. In total, Liu et al included 5993 participants older than 20 years in which they measured lung function via spirometry. Making use of this large number of participants from a wellconducted study with detailed air pollution measurements, they could show that increased PM concentrations were significantly associated with increased COPD prevalence and declined respiratory function. Furthermore, Liu et al found that the increased daily mean PM2.5 and PM10 levels were associated with an increased risk of COPD symptoms and other chronic pulmonary diseases. Looking forward, Liu et al stated that further research is needed to clarify the differential susceptibility to these pollutants and individual exposure differences and to explore possible pathogenic mechanisms of COPD triggered by airborne particulate matter.

The identification of susceptible subgroups is an important public health issue for the development of adequate strategies for both disease prevention as well as disease treatment. Adam et al, ${ }^{10}$ for example, suggested, in a publication based on the ESCAPE study, that obese persons were particularly sensitive to air pollution. Therefore, change in lifestyle or nutrition, for example, intake of antioxidant-rich diets (leafy vegetables and fruits) as reported by Guan et al, ${ }^{7}$ might prevent the adverse effects of air pollution or help people with air pollution induced lung function decline to increase their quality of life. Furthermore, to combat the effect of air pollution on the airway, more research is needed for development of strategies and therapeutic approaches for decreasing neutrophilic inflammation in COPD. One example was a pilot human study on the use of inhaled ectoine. $^{13}$

Another field of growing interest is the study of gene-environment interactions to identify genetic subgroups that are more susceptible to air pollution induced COPD. This might help us to understand the pathogenic mechanisms of COPD and could inform the development of personalised medicine. However, until now there are very few studies on this important topic. ${ }^{14-17}$

The majority of studies on the effects of air pollution on COPD in China have one limitation in common, namely, they are all based on cross-sectional data. So far, there has been no long-term cohort study of respiratory health and air pollution in China, and the few cross-sectional studies that used long-term exposure to air pollution are difficult to interpret due to the lack of adjustment for potential confounders. ${ }^{18}$ There is an urgent need to conduct long-term cohort studies in countries with extremely high levels of air pollution, such as China and India.

In conclusion, Liu et al provide an important contribution to the evidence that high levels of air pollution in low/ middle-income countries like China cause severe health problems like COPD. In Europe, it has already been shown that decreasing exposure to airborne particulates appears to attenuate the decline in lung function related to exposure to PM10. ${ }^{19}$ The ambition and capacity of successful management of air pollution in China might serve as an example for low/ middle-income countries. ${ }^{7}$

Contributors $\mathrm{AH}$ and TS wrote the initial draft and had final responsibility for the decision to submit for publication.

Competing interests None declared.

Provenance and peer review Commissioned; externally peer reviewed.

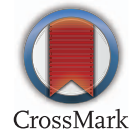

To cite Hüls A, Schikowski T. Thorax 2017;72:771-772.

Published Online First 25 April 2017

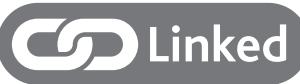

- http://dx.doi.org/10.1136/thoraxjnl-2016-208910

Thorax 2017:72:771-772

doi:10.1136/thoraxjnl-2016-209687

\section{REFERENCES}

1 López-Campos JL, Tan W, Soriano JB. Global burden of COPD. Respirology 2016;21:14-23. 
2 Burney PGJ, Patel J, Newson R, et al. Europe PMC funders group global and regional trends in chronic obstructive pulmonary disease mortality 1990-2010. Eur Respir J 2015;45:1239-47.

3 Zhou M, Wang H, Zhu J, et al. Cause-specific mortality for 240 causes in China during 19902013: a systematic subnational analysis for the Global Burden of Disease Study 2013. Lancet 2016;387:251-72.

4 Eisner MD, Anthonisen N, Coultas D, et al. An official American Thoracic Society public policy statement: novel risk factors and the global burden of chronic obstructive pulmonary disease. Am J Respir Crit Care Med 2010;182:693-718.

5 Berend N. Contribution of air pollution to COPD and small airway dysfunction. Respirology 2016;21:237-44

6 Xu W, Wu Q, Liu X, et al. Characteristics of ammonia, acid gases, and PM2.5 for three typical land-use types in the North China Plain. Environ SCi Pollut Res Int 2016;23:1158-72.

7 Guan WJ, Zheng XY, Chung KF, et al. Impact of air pollution on the burden of chronic respiratory diseases in China: time for urgent action. Lancet 2016;388:1939-51.
8 Ko FWS, Hui DSC. Air pollution and chronic obstructive pulmonary disease. Respirology 2012;17:395-401.

9 Schikowski T, Adam M, Marcon A, et al. Association of ambient air pollution with the prevalence and incidence of COPD. Eur Respir J 2014;44:614-26.

10 Adam M, Schikowski T, Carsin AE, et al. Adult lung function and long-term air pollution exposure. ESCAPE: a multicentre cohort study and meta-analysis. Eur Respir J 2015;45:38-50.

11 Götschi T, Heinrich J, Sunyer J, et al. Long-term effects of ambient air pollution on lung function: a review. Epidemiology 2008;19:690-701.

12 Liu S, Zhou Y, Liu S, et al. Association between exposure to ambient particulate matter and chronic obstructive pulmonary disease: results from a cross-sectional study in China. Thorax 2017;72:788-95.

13 Unfried K, Krämer U, Sydlik U, et al. Reduction of neutrophilic lung inflammation by inhalation of the compatible solute ectoine: a randomized trial with elderly individuals. Int I Chron Obstruct Pulmon Dis 2016;11:2573-83.
14 Hüls A, Krämer U, Herder C, et al. Genetic susceptibility for air pollution-induced airway inflammation in the SALIA study. Environ Res 2017;152:43-50.

15 Kim HJ, Min JY, Min KB, et al. CDH13 gene-byPM10 interaction effect on lung function decline in Korean men. Chemosphere 2017;168: 583-9.

16 Thun GA, Imboden M, Künzli N, et al. Follow-up on genome-wide main effects: do polymorphisms modify the air pollution effect on lung function decline in adults?. Environ Int 2014;64:110-15.

17 Curjuric I, Imboden M, Nadif R, et al. Different genes interact with particulate matter and tobacco smoke exposure in affecting lung function decline in the general population. PLOS ONE 2012;7: e40175.

18 Kan $\mathrm{H}$, Chen B, Hong C. Health impact of outdoor air pollution in China: current knowledge and future research needs. Environ Health Perspect 2009;117: A187.

19 Downs SH, Schindler C, Liu LJ, et al. Reduced exposure to PM10 and attenuated age-related decline in lung function. $N$ Eng/ J Med 2007;357:2338-47. 